\title{
Analisa Kadar Vitamin D 25 (OH) Total Pada Pasien Usia 10-19 Tahun Yang Melakukan Pemeriksaan di Prodia Kelapa Gading-Jakarta
}

\author{
Enny Khotimah, Leli Rahayu \\ Program Studi DIV Teknologi Laboratorium Medik Universitas Binawan \\ Email : ennykesehatan17@gmail.com
}

\begin{abstract}
Abstrak
Masalah ketidakcukupan vitamin D mempengaruhi hampir $50 \%$ dari populasi di seluruh dunia di semua etnis dan kelompok umur serta mendapat perhatian dari beberapa negara di dunia saat ini, khususnya anak-anak usia remaja rentang usia 10 - 19 tahun. Defisiensi vitamin $\mathrm{D}$ pada tubuh manusia bisa menyebabkan penyakit. Oleh karena itu, kadar vitamin $\mathrm{D} 25(\mathrm{OH})$ total $<10 \mathrm{ng} / \mathrm{mL}$ menunjukkan difiesiensi vitamin $\mathrm{D}$ yang dapat menyebabkan Rickets (Anak-anak) dan Osteomalcia (Orang dewasa). Usia remaja penting melakukan pemeriksaan vitamin D sebagai deteksi dini pada masa pertumbuhan, karena pada usia remaja, massa dan kepadatan tulang belum maksimal.

Penelitian ini bertujuan untuk menganalisa status vitamin D $25(\mathrm{OH})$ total pada usia remaja 10-19 tahun serta faktor prilaku yang mempengaruhi. Data yang digunakan yaitu data sekunder dari sistem LIS Laboratorium Prodia Kelapa Gading pada bulan Januari 2017 sampai Mei 2020.

Desain penelitian adalah deskriptif cross sectional menggunakan 356 orang responden menggunakan analisis univariat yang menggambarkan status vitamin D $25(\mathrm{OH})$ total pada usia remaja 10-19 tahun.

Hasil analisis menunjukkan defisiensi vitamin D $25(\mathrm{OH})$ total $(0-12 \mathrm{ng} / \mathrm{mL})$ sebanyak 33 pasien (9.3\%); insufisiensi (12.1-20.9 ng/mL) sebanyak 156 (43.8\%) dan sufisiensi sebanyak 167 (46.9\%). Dari hasil tersebut dapat menunjukkan bahwa status vitamin D pada anak usia remaja 10-19 tahun perlu mendapat perhatian agar tidak terjadi peningkatan kasus defisiensi vitamin D di usia tersebut.
\end{abstract}

Kata kunci : Status Vitamin D $25(\mathrm{OH})$ total, Usia remaja 10-19 tahun ,Perilaku hidup tidak sehat usia remaja

\begin{abstract}
Vitamin D insufficiency problem affects nearly $50 \%$ of the population worldwide in all ethnic and age groups and is getting attention from several countries in the world today, especially children aged 10-19 years. Deficiency of vitamin $D$ in the human body can cause disease. Therefore, a total vitamin $D 25(\mathrm{OH})$ level $<10 \mathrm{ng} / \mathrm{mL}$ indicates a vitamin D deficiency that can lead to Rickets (Children) and Osteomalcia (Adults). Adolescence is important to do vitamin $\mathrm{D}$ examination as early detection during growth period, because in adolescence, bone mass and density are not maximized.

This study aims to analyze the total vitamin D $25(\mathrm{OH})$ status in adolescents $10-19$ years and the behavioral factors that influence it. The data used are secondary data from the LIS system of Prodia Kelapa Gading Laboratory from January 2017 to May 2020. The research design was cross sectional descriptive using 356 respondents. The data were analyzed using univariate analysis describing total vitamin D $25(\mathrm{OH})$ status in adolescents 10-19 years.
\end{abstract}

http://ejournal.urindo.ac.id/index.php/kesehatan

Article History :

Sumbitted 31 Oktober 2020, Accepted 30 Desember 2020, Published 31 Desember 2020 


\section{Jurnal Bidang Ilmu Kesehatan}

The analysis showed that total vitamin D deficiency $25(\mathrm{OH})(0-12 \mathrm{ng} / \mathrm{mL})$ in 33 patients (9.3\%); insufficiency (12.1-20.9 $\mathrm{ng} / \mathrm{mL}$ ) as many as 156 people (43.8\%) and sufficiency as many as 167 people (46.9\%). From these results, it can be shown that vitamin D status in adolescents aged 10-19 years needs attention so that there is no increase in cases of vitamin $D$ deficiency at that age.

Key words: Total $25(\mathrm{OH})$ Vitamin D status, 10-19 years of adolescence, adolescent unhealthy life behavior.

\section{PENDAHULUAN}

Masalah ketidak cukupan vitamin D mempengaruhi hampir $50 \%$ dari populasi di seluruh dunia dan menjadi topik yang cukup dibicarakan tidak hanya di luar negeri tapi negara sub-tropis maupun tropis ditemukan adanya peningkatan prevalensi kekurangan vitamin D.

Defisiensi vitamin D disebabkan karena rendahnya asupan makanan yang mengandung vitamin $D$ antara lain ikan berlemak, susu dan makanan yang difortifikasi, dan adanya kecenderungan mengurangi bahan makanan tinggi lemak. Vitamin D pada manusia didapatkan melalui asupan makanan dan paparan sinar matahari. Vitamin $D$ terbagi menjadi dua bentuk yaitu Vitamin ergocalciferol (D2) dan cholecalciferol (D3).

Vitamin D tidak hanya didapatkan dari makanan atau suplemen yang mengandung vitamin D2 atau D3. Tetapi, vitamin D dapat dihasilkan dikulit dalam bentuk cholecalciferol (D3) sedangkan ergocalciferol atau vitamin D2 dapat ditemukan pada tumbuhan melalui paparan sinar UVB pada steroid.
Minyak ikan cod dan 'oily fish' pada ikan salmon, mackerel, serta ikan sarden dapat dikonsumsi 3-4 kali per minggu untuk memenuhi standar asupan vitamin D yang dibutuhkan oleh tubuh. Beberapa makanan dan minuman lainnya yang mengandung vitamin D yaitu kuning telur, jamur, hati sapi, udang, keju, mentega, susu (100 IU / 8oz), jus jeruk (100 IU / 8 oz), beberapa sereal, margarin dan roti.

Kekurangan vitamin D dalam tubuh manusia menyebabkan banyak penyakit. Jika kadar vitamin $D 25(\mathrm{OH})$ total $<10 \mathrm{ng} / \mathrm{mL}$ dapat menyebabkan rakhitis pada anak dan osteomalcia pada orang dewasa. Rakhitis merupakan pelunakan tulang pada anak karena kekurangan vitamin $D$ sehingga berakibat patah tulang dan kelainan bentuk sedangkan osteomalcia adalah kelainan pada tulang orang dewasa akibat kekurangan vitamin $D$ sehingga tulang mudah rapuh dan patah.

Kekurangan vitamin D pada anak menjadi ancaman bagi Indonesia karena dapat menghambat pertumbuhan serta memicu penyakit tulang. Kekurangan vitamin 
D juga mendorong timbulnya penyakit lain seperti penyakit kardiovaskular, gejala dyslipidemia, diabetes, dan hipertensi.

Pencegahan terhadap kucukupan atau kekurangan vitamin $\mathrm{D}$ dapat dilakukan dengan pemberian suplementasi vitamin D (400 IU per hari), bayi mendapatkan ASI yang cukup, meningkatkan paparan terhadap sinar matahari. Baiknya, paparan sinar matahari berdasarkan ras yaitu untuk kulit putih sekitar 30 menit dilakukan 3 kali seminggu sementara untuk kulit hitam dilakukan 5-10 kali lebih lama.

Kebutuhan vitamin D dan kalsium dapat terpenuhi jika kepedulian dan edukasi kepada masyarakat mengenai vitamin $D$ dan kalsium terus ditingkatkan, selain itu perlu kerjasama dengan berbagai pihak untuk memberlakukan pihak sekolah pada saat jam tertentu membuat program "berjemur" bersama dengan estimasi waktu yang sesuai dengan kondisi sinar matahari dan juga dibutuhkan sumbangan untuk mendukung pemberian makanan sehat serta pemberian suplemen pada bayi sejak lahir untuk mencegah terjadinya kekurangan vitamin D $25(\mathrm{OH})$ total.

\section{METODE PENELITIAN}

Desain penelitian yaitu deskriptif kualitatif dengan pendekaan cross sectional , variabel yang diteliti yaitu kadar vitamin D 25 $(\mathrm{OH})$ total pada pasien usia remaja 10-19 tahun..
Populasi umum pada penelitian ini adalah pasien usia remaja (10-19 tahun) yang melakukan pemeriksaan Vitamin D $25(\mathrm{OH})$ total di Laboratorium Prodia Kelapa GadingJakarta

Sampel penelitian berupa hasil pemeriksaan laboratorium pasien usia remaja 10 - 19 tahun yang melakukan pemeriksaan Vitamin D $25(\mathrm{OH})$ total, dengan periode waktu Januari 2017 - Januari 2020. Variabel yang diteliti adalah :

1. Kadar vitamin $D 25(\mathrm{OH})$ total sebagai variabel terikat .

2. Usia remaja 10-19 tahun sebagai variabel bebas .

Data penelitian berupa data sekunder yang didapatkan dari sistem LIS (Laboratorium Informasi Sistem) Prodia Kelapa Gading Jakarta pada bulan Januari 2017 - Mei 2020 , dengan kategori usia remaja 10-19 tahun. Analisis data berupa analisis univariat untuk mendeskripsikan variabel agar diketahui distribusi dan persentase dari tiap variabel dalam bentuk tabel dan grafik.

$$
\text { Analisis univariat dilakukan }
$$

perhitungan dengan rumus berikut (Notoatmodjo, 2010) :

$$
P=\frac{X}{N} \times 100 \%
$$

Keterangan :

P: Presentase

$X$ : Jumlah kejadian pada responden

$\mathrm{N}$ : Jumlah seluruh responden 
Jurnal Bidang IImu Kesehatan

HASIL

Tabel 1 Status Vitamin D $25(\mathrm{OH})$ total

\begin{tabular}{lcc}
\hline & Jumlah responden & $\%$ \\
\hline Defisiensi $(0-11.9 \mathrm{ng} / \mathrm{mL})$ & 33 & 9.3 \\
Insufisiensi $(12-20.9 \mathrm{ng} / \mathrm{mL})$ & 156 & 43.8 \\
Sufisiensi $(21-100 \mathrm{ng} / \mathrm{mL})$ & 167 & 46.9 \\
\hline Total & $\mathbf{3 5 6}$ & $\mathbf{1 0 0}$ \\
\hline
\end{tabular}

Tabel 1 menunjukkan status vitamin D $25(\mathrm{OH})$ total pada 356 orang responden yang mengikuti penelitian, yaitu dengan kondisi defisiensi $(0-12 \mathrm{ng} / \mathrm{mL})$ sebanyak 33 orang
(9.3\%); insufisiensi(12.1-20.9 ng/mL) sebanyak 156 orang (43.8\%) dan sufisiensi sebanyak 167 orang (46.9\%).

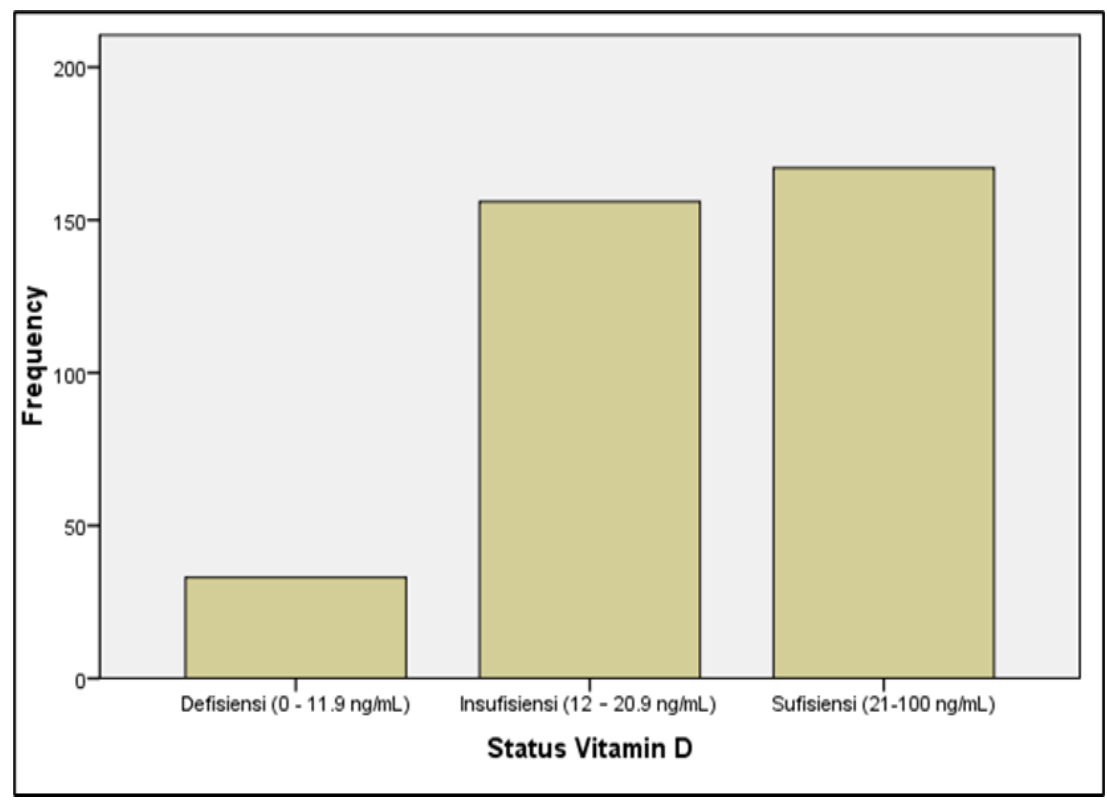

Gambar 1. Grafik status vitamin D $25(\mathrm{OH})$ total

Gambar 1 menunjukkan grafik status vitamin

D $25(\mathrm{OH})$ total pada 356 orang responden, dari gambaran grafik di dapatkan kondisi defisiensi dan insufisiensi mencapai $53.1 \%$ $(189$ orang responden

Tabel 2. Status vitamin D $25-\mathrm{OH}$ total berdasarkan jenis kelamin

\begin{tabular}{lccccccc}
\hline & Defisiensi & & Insufisiensi & & Sufisiensi & & Total \\
\cline { 2 - 8 } & $\begin{array}{c}\text { Jumlah } \\
\text { responden }\end{array}$ & $\%$ & $\begin{array}{c}\text { Jumlah } \\
\text { responden }\end{array}$ & $\%$ & $\begin{array}{c}\text { Jumlah } \\
\text { responden }\end{array}$ & $\%$ & \\
\hline Laki-laki & 10 & 6 & 61 & 36.7 & 95 & 57.2 & 166
\end{tabular}


Tabel 2 menunjukkan status vitamin

D 25-OH total pada Laki-laki berjumlah 166 pasien (46.6\%) dan perempuan 190 pasien (53.4\%) dengan rincian sebagai berikut : Lakilaki dengan kondisi defisiensi sebanyak 10 pasien (6.0\%); laki-laki dengan insufisiensi sebanyak 61 pasien (36.7\%); laki-laki dengan sufisiensi sebanyak 95 pasien (57.2\%), sedangkan untuk perempuan yang mengalami defisiensi sebanyak 23 pasien (12.1\%) ; perempuan dengan insufisiensi sebanyak 95 pasien $(50.0 \%)$ dan perempuan dengan status vitamin D sufisiensi sebanyak 72 pasien (37.9\%).

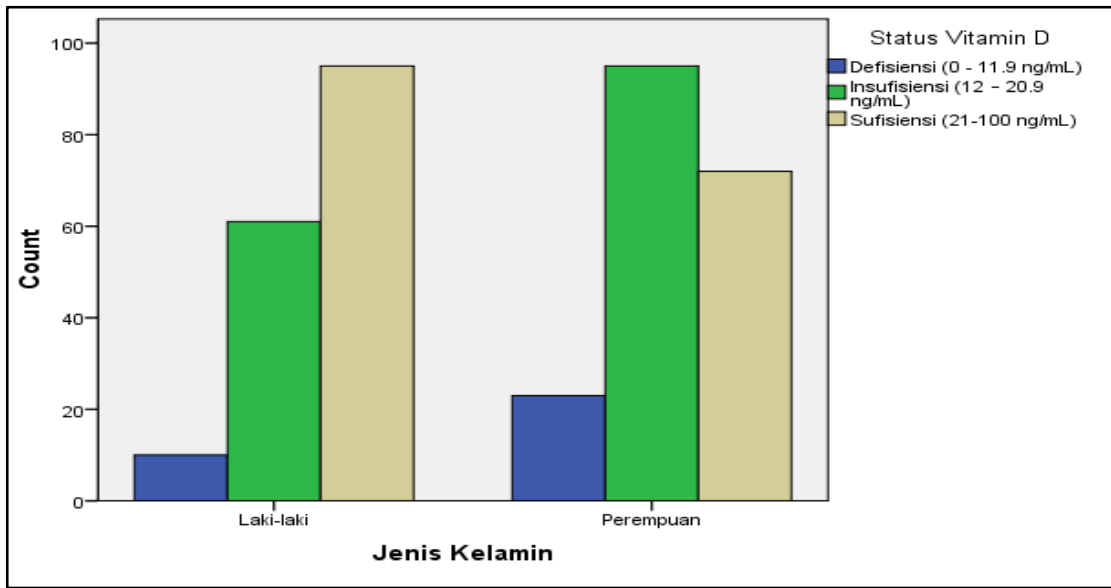

Gambar 2. Grafik sebaran status vitamin D berdasarkan jenis kelamin.

Gambar

2.menunjukkan grafik

didapatkan pada perempuan mengalami sebaran data status vitamin D $25-\mathrm{OH}$ total kasus defisiensi dan insufisiensi lebih tinggi berdasarkan jenis kelamin.Gambaran grafik dibanding laki-laki.

Tabel 3 Kategori usia responden dengan status vitamin D 25(OH) total

\begin{tabular}{cccccccc}
\hline & \multicolumn{2}{c}{ Defisiensi } & \multicolumn{2}{c}{ Insufisiensi } & \multicolumn{2}{c}{ Sufisiensi } & Total \\
\cline { 1 - 5 } $\begin{array}{c}\text { Usia } \\
\begin{array}{c}\text { Responden } \\
\text { Tahun) }\end{array}\end{array}$ & $\begin{array}{c}\text { Jumlah } \\
\text { responden }\end{array}$ & $\%$ & $\begin{array}{c}\text { Jumlah } \\
\text { responden }\end{array}$ & $\%$ & $\begin{array}{c}\text { Jumlah } \\
\text { responden }\end{array}$ & $\%$ & \\
\hline 10 & 1 & 5.3 & 6 & 31.6 & 12 & 63.2 & 19 \\
11 & 1 & 2.9 & 18 & 52.9 & 15 & 44.1 & 34 \\
12 & 5 & 16.7 & 8 & 26.7 & 17 & 56.7 & 30 \\
13 & 1 & 3.2 & 15 & 48.4 & 15 & 48.4 & 31 \\
14 & 2 & 5.4 & 21 & 56.8 & 14 & 37.8 & 37 \\
15 & 9 & 22.5 & 11 & 27.5 & 20 & 50 & 40 \\
16 & 0 & 0 & 15 & 46.9 & 17 & 53.1 & 32
\end{tabular}




\begin{tabular}{llcccccc}
17 & 3 & 7.7 & 18 & 46.2 & 18 & 46.2 & 39 \\
18 & 2 & 4.1 & 24 & 49 & 23 & 46.9 & 49 \\
19 & 9 & 20 & 20 & 44.4 & 16 & 35.6 & 45 \\
\hline \multicolumn{7}{c}{ Total } \\
\hline
\end{tabular}

Tabel 3 menunjukkan kategori usia responden yang mengikuti penelitian, yaitu usia 10 tahun sebanyak 19 pasien (5.3\%); 11 tahun sebanyak 34 pasien (9.6\%); 12 tahun sebanyak 30 pasien (8.4\%); usia 13 tahun sebanyak 31 pasien (8.7\%); usia 14 tahun sebanyak 37 pasien (10.4\%); usia 15 tahun sebanyak 40 pasien (11.2\%); usia 16 tahun sebanyak 32 pasien (9.0\%); usia 17 tahun sebanyak 39 (11.0\%); usia 18 tahun sebanyak 49 pasien (13.8\%) dan usia 19 tahun sebanyak 45 pasien

(12.6\%).

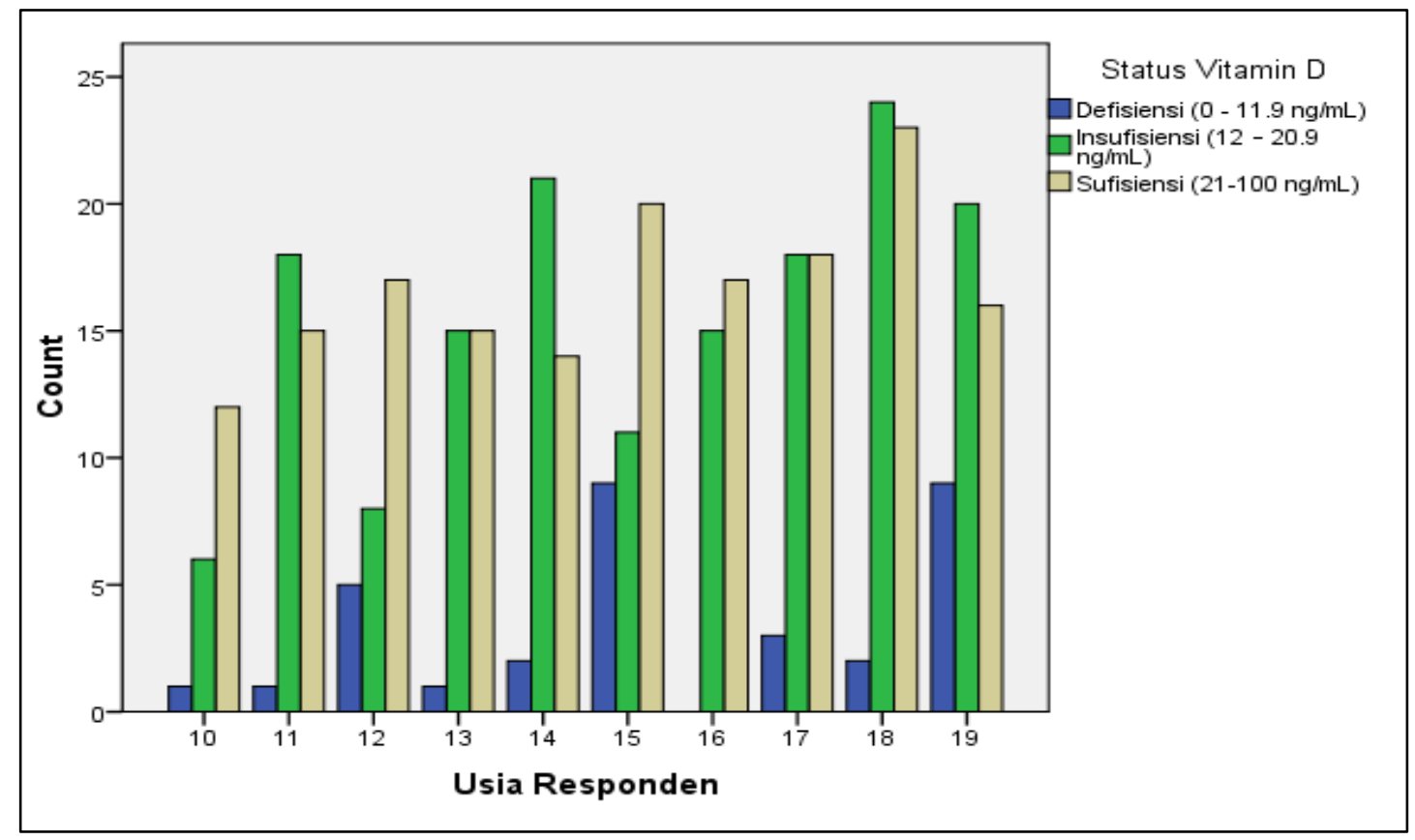

Gambar 3. Grafik sebaran status vitamin D 25(OH) total berdasarkan usia responden

Gambar 3 menunjukkan grafik sebaran data status vitamin $\mathrm{D} 25(\mathrm{OH})$ total berdasarkan usia responden.

Gambaran grafik menunjukkan yang mendominasi yaitu pada kategori usia 18 tahun sebanyak 49 orang responden (13.8\%) dari total 356 orang responden yang mengikuti penelitian.

Responden yang mengalami kondisi defisiensi sebanyak 2 orang (4.1\%) , insufisiensi sebanyak 24 orang (49\%) dan sufisiensi 23 orang $(46.9 \%)$ 


\section{PEMBAHASAN}

Hasil status vitamin D $25(\mathrm{OH})$ total pada jenis kelamin laki-laki dan perempuan mengalami kondisi kekurangan (defisiensi) vitamin D sebanyak 33 orang (9.3\%) dan yang mengalami ketidak cukupan (Insufisiensi) sebanyak 156 orang (43.8\%).

Ternyata hal ini sejalan dengan beberapa penelitian sebelumnya bahwasanya kasus defisiensi dan insufisiensi vitamin D 25 $(\mathrm{OH})$ total pada usia remaja 10-19 tahun masih cukup tinggi khususnya wilayah Kelapa Gading dan sekitarnya.

Batasan status vitamin D yang digunakan dalam artikel ini sebagai berikut, defisiensi vitamin D jika kadar vitamin D 25 $(\mathrm{OH})$ total pada hasil pemeriksaan laboratorium < $12 \mathrm{ng} / \mathrm{ml}$, insufisiensi bila kadar vitamin D 25(OH) Total dan sufisiensi/cukup bila kadar vitamin D $25(\mathrm{OH})$ Total $21-100 \mathrm{ng} / \mathrm{ml}$.

Referensi penelitian sebelumnya dilakukan di kota depok, peneliti menemukan bahwa status vitamin D pada remaja sehat didapatkan sebanyak $43,3 \%$ berada dalam status defisiensi dan $21,7 \%$ insufisiensi.

Data penelitian ini (gambar 3) pada usia responden 18 tahun paling banyak mengalami kondisi defisiensi dan insufisiensi vitamin D.

Data penelitian ini (gambar 3) dapat dikatakan bahwa kadar vitamin D $25(\mathrm{OH})$ total pada anak-anak usia 10 - 19 tahun dalam keadaan tidak mencukupi untuk memenuhi kebutukan optimal, keadaan ini apabila terus berlanjut akan menjadi keadaan yang mengkhawatirkan yaitu terjadinya keadaan anak kekurangan vitamin D.

\section{SIMPULAN}

Hasil analisa data dapat disimpulkan sebagai berikut :

1.Status vitamin D $25(\mathrm{OH})$ total dilihat dari jumlah keseluruhan responden yaitu yang mengalami defisiensi sebanyak 33 orang (9.3\%); insufisiensi 156 orang (43.8\%) dan sufisiensi sebanyak 167 orang (46.9\%)

2.Status vitamin D $25(\mathrm{OH})$ total berdasarkan jenis kelamin responden yaitu, : Laki-laki sebanyak 166 pasien (46.6\%) dari jumlah total 356 responden, defisiensi sebanyak 10 pasien (2.8\%); insufisiensi sebanyak 61 pasien (17.1\%); dan sufisiensi sebanyak 95 pasien (26.7\%).

Perempuan sebanyak 190 pasien (53.4\%).dari jumlah total 356 responden dengan rincian sebagai berikut: defisiensi sebanyak 23 pasien (6.5\%) insufisiensi sebanyak 95 pasien (26.7\%) dan sufisiensi sebanyak 72 pasien (20.2\%).

3.Status vitamin D $25(\mathrm{OH})$ total berdasarkan kategori usia responden yaitu, :

-Usia 10 tahun 19 pasien (5.3\%) : Defisiensi 1 pasien $(0.3 \%)$, Insufisiensi 6 pasien (1.7\%) dan Sufisiensi 12 pasien (3.4\%)

-Usia 11 tahun 34 pasien (9.6\%) : Defisiensi 1 pasien (0.3\%), Insufisiensi 18 pasien (5.1\%) dan Sufisiensi 15 pasien (4.2\%)

-Usia 12 tahun 30 pasien (8.4\%) : Defisiensi 5 
pasien (1.4\%), Insufisiensi 8 pasien (2.2\%) dan Sufisiensi 17 pasien (4.8\%)

-Usia 13 tahun 31 pasien (8.7\%) : Defisiensi 1 pasien (0.3\%), Insufisiensi 15 pasien (4.2\%) dan Sufisiensi 15 pasien (4.2\%)

-Usia 14 tahun 37 pasien (10.4\%) : Defisiensi 2 pasien (0.6\%), Insufisiensi 21 pasien (5.9\%) dan Sufisiensi 14 pasien (3.9\%)

-Usia 15 tahun 40 pasien (11.2\%) : Defisiensi

9 pasien (2.5\%), Insufisiensi 11 pasien (3.1 \%) dan Sufisiensi 20 pasien (5.6\% )

-Usia 16 tahun 32 pasien (9.0\%) : Defisiensi tidak ada pasien (0\%), Insufisiensi 15 pasien (4.2\%) dan Sufisiensi 17 pasien (4.8\% )

-Usia 17 tahun 39 pasien (11.0\%) : Defisiensi 3 pasien (0.8\%), Insufisiensi 18 pasien (5.1\%) dan Sufisiensi 18 pasien (5.1\%)

-Usia 18 tahun 49 pasien (13.8\%) : Defisiensi 2 pasien (0.6\%), Insufisiensi 24 pasien (6.7\%) dan Sufisiensi 23 pasien (6.5\%)

-Usia 19 tahun 45 pasien (12.6\%) : Defisiensi 9 pasien (2.5\%), Insufisiensi 20 pasien (5.6\%) dan Sufisiensi 16 pasien (4.5\% ).

Hasil pemeriksaan vitamin D $25(\mathrm{OH})$ total dapat menjadi data pendukung untuk pemantauan pengobatan terhadap penyakit dan menjadi acuan pemberian suplemen bagi pasien.

\section{DAFTAR PUSTAKA}

Nair R, Maseeh A. Vitamin D: The "sunshine" vitamin. J Pharmacol Pharmacother. 2012; 118-26
Khor, Thuy.Vitamin D Deficiency and Health Outcomes in Asia. Conference Vitamin D and Health Jakarta.2011.

Oemardi $M$, Horowitz $M$, Wishart JM, Morris HA, Need AG, O'Loughlin PD, Nordin B. The effect of menopause on bone mineral density and bone-related biochemical variables in Indonesian women. Clinical Endocrinology. 2007;67(1):93-100.

Setiati S. Vitamin D status among Indonesian elderly women living in institutionalized care units. Population. 2008;40(2).

Green TJ, Skeaff CM, Rockell JE, Venn BJ, Lambert A, Todd J, et al. Vitamin D status and its association with parathyroid hormone concentrations in women of child-bearing age living in Jakarta and Kuala Lumpur. European Journal of Clinical Nutrition. 2008;62(3):373378

Saptarini D.Status Vitamin D pada Remaja Sehat Usia 15-18 Tahun di Kota Depok. Jurnal Indon Med Assoc.2019:69(2)

Sharma RK, Dogra S, Singh A KA. Epidemiological patterns of acne vulgaris among adolescents in North India: A cross sectional study and brief review of literature. Indian J Paediatr Dermatol. 2017;18:196-201

Holick MF, Chen TC, Lu Z, Sauter E. Vitamin D and skin physiology: a D-lightful story. J Bone Miner Res. 2007;22 (Suppl 2):S28$3 \mathrm{S3}$

Holick MF. Vitamin D deficiency. N Engl J Med. 2007;357:266-281.

Holick MF: High prevalence of vitamin D inadequacy and implications for health. Mayo Clin Proc. 2006;81:353-373

Holick MF. Sunlight and vitamin D for bone health and prevention of autoimmune diseases, cancers, and cardiovascular disease. The American Journal of Clinical Nutrition. 2004;80(6):1678S-1688S 
Batubara, Jose RL. Adolescent Development (Perkembangan Pediatri.2010:12(1)

Stroud M. Vitamin D - a review. Australian Family Physician. 2008; 37(12): 1002-5. 11.Major GC, Francine

Soesanti F,Pulungan A,Trijaya B,Batubara,Jose RL. Vitamin $D$ profile in healthy children aged 7-12 years old in Indonesia. International Journal of Pediatric Endocrinology.2013:167

R. Z, D.P. N. Vitamin D in health and disease: Current perspectives. Nutr J. 2010; 9: 65.

Chaudhuri K, Ashok L, Sujatha G. The sunshine of life: Vitamin D. Int J Oral Heal Sci [Internet].2015;5(1):30.Available from:http://www.ijohsjournal.org/text.a sp?2015/5/1/30/ 171171.

Al-Shoumer KA. Is there a relationship between vitamin $D$ with insulin resistance and diabetes mellitus? World J Diabetes. 2015.

Matsuoka LY, Wortsman J, Dannenberg MJ, Hollis BW, Lu Z, Holick MF. Clothing prevents ultraviolet- $B$ radiationdependent photosynthesis of vitamin D3. J Clin Endocrinol Metab. 1992; 6(8): 1057-64

Grooper SS, Smith JL GJ. Advanced nutrition and human metabolism. Vitamion D. 5th ed. Canada: Wadsworth, Cengage Learning; 2009.p.3920400

Misra M, Pacaud D, Petryk A, Collett-Solberg PF, Kappy M. Vitamin D Deficiency in Children and Its Management: Review of Current Knowledge and Recommendations. Pediatrics. 2008; 398-417.

Vieth R, Bischoff-Ferrari H, Boucher BJ. Erratum: The urgent need to recommend an intake of vitamin $D$ that is effective (American Journal of Clinical Nutrition
(2007) 85, 649650)). American Journal of Clinical Nutrition. 2007. 85(3):649-50.

Faustino R Pérez-López, Gonzalo Pérez-Roncero and MTLB. Vitamin $D$ and adolescent health. Adolesc Heal Med Ther. 2010;1:1-8.

S Setiati1 MD, PhD, M Oemardi2 MD, B Sutrisna3 MD, PhD, Supartondo4 MD. The role of ultraviolet- $B$ from sun exposure on vitamin D3 and parathyroid hormone level in elderly women in Indonesia. Asian J Gerontol Geriatri 2007; 2: 126-32

Badan Standardisasi Nasional. Laboratorium medik - Persyaratan mutu dan kompetensi SNI ISO 15189:2012: 5

Normogram Eppendorf Germany. Copyright (C) 2017 by Eppendorf AG.

http://cmpt.ca/extending-the-scope-of-eqa-tothe-extra-analytical-phases/ by Veronica Restelli Extending the scope of EQA to the ekstra analytical phase,November 2017

Triana Vivi, Studi Literatur macam-macam vitamin dan fungsinya dalam tubuh manusia, Jurnal Kesehatan Masyarakat, September 2006, I (1)

Wahidah, Hubungan Antara Masa Pubertas Dengan Perilaku Diet Pada Remaja Putri Di SMAN 2 Woha, Palapa: Jurnal Studi Keislaman dan Ilmu Pendidikan Volume 6, Nomor 1, Mei 2018

Sugiyono, 2008, Metode Penelitian Kuantitatif, Kualitatif dan R\&D, Bandung : Alfabeta.

Sukmadinata, N.S. 2011. Metode Penelitian Pendidikan. Bandung: Remaja Rosadakarya 